\title{
Criterios de imputación objetiva en el derecho de daños de España y Colombia
}

DOI: dx.doi.org/10.15425/2017.354

\section{Resumen}

Este artículo tiene por objeto establecer un análisis comparativo de la causalidad e imputación objetiva en el derecho de daños de España y Colombia. En la primera parte se hace un excurso por las tradicionales teorías de la causalidad en la doctrina y el derecho comparado. En el segundo apartado se elabora el concepto de imputación objetiva en el derecho de daños al tiempo que se establecen diferencias con su equivalente en el derecho penal. En la tercera parte se analizan los criterios de imputación objetiva bajo el tamizaje de la doctrina y la jurisprudencia comparadas. Finalmente, deja planteado un estado del arte de la imputación objetiva en el derecho de daños colombiano.

\section{Palabras clave}

Causalidad, causalidad adecuada, criterios de imputación, daños, equivalencia de las condiciones, imputación objetiva. 


\title{
Criteria for objective imputation in the tort law of Spain and Colombia
}

\begin{abstract}
The purpose of this article is to establish a comparative analysis of the causation and objective imputation of the tort law of Spain and Colombia. The first part takes the traditional theories of causation in doctrine and comparative law. The second paragraph elaborates the concept of an objective imputation in the tort law while making differences with its equivalent in criminal law. The third part analyses the criteria for objective imputation under the screening of comparative doctrine and jurisprudence. Finally, it raises a state of the art of the objective imputation in the Colombian tort law.
\end{abstract}

\section{Keywords}

Adequacy theory, causation, equivalence theory, imputation criteria, objective imputation, torts.

Siglas

ADC: Anuario de Derecho Civil

AP: Audiencia Provincial

BGB: Código Civil de Alemania (Bürgerliches Gesetzbuch)

CC: Código Civil

CSJ: Corte Suprema de Justicia de Colombia

TSE: Tribunal Supremo español 


\section{Introducción}

Los códigos civiles de España y Colombia comparten su orientación francesa siguiendo al Code en la mayor parte de sus instituciones, pero en especial en lo relativo a las obligaciones y responsabilidad civil extracontractual ${ }^{1}$.

Los sistemas de orientación francesa se rigen por una cláusula general de responsabilidad civil que proporciona unos elementos esenciales para establecer cuándo existe la obligación de reparar un daño. Los sistemas de cláusula general también se conocen como abiertos o atípicos y se caracterizan por que las conductas que originan la obligación no están enlistadas taxativamente en el ordenamiento jurídico, así como tampoco los daños resarcibles.

Por regla general los sistemas atípicos no exigen la antijuridicidad como elemento esencial de la responsabilidad civil; en España la opinión dominante ${ }^{2}$ considera que son daños resarcibles todos aquellos que se funden sobre un interés a menos que éste devenga ilícito.

En Colombia sería aplicable el mismo planteamiento, puesto que ninguna mención hace el artículo $2341^{[3]}$ del CC sobre la ilicitud del daño o la conducta. No se requiere la violación de una norma, lesión de un derecho subjetivo o interés, para que surja la obligación de reparar un daño.

La ausencia de antijuridicidad en los sistemas de responsabilidad que analizamos resulta una precisión útil porque puede llegar a confundirse la imputación objetiva con el juicio de culpabilidad. No desconocemos que existen posturas ${ }^{4}$ que preconizan la idea de la antijuridicidad como elemento de la responsabilidad civil en el derecho de daños español, pero consideramos que tal visión no resulta conciliable con el concepto de imputación objetiva.

1 Mariano Alonso, "Ideal codificador", en Centenario del código civil, t. I (Madrid: Ramón Areces, 1990), 25 y Carlos Petit Calvo, “España y el code de Napoleón”, Anuario de Derecho Civil 61, n. ${ }^{\circ} 4$ (2008): 1827, https://dialnet.unirioja.es/descarga/articulo/2947322.pdf.

2 Fernando Pantaleón, "De las obligaciones que nacen por culpa o negligencia”, en Comentario del código civil, dirigido por Cándido Paz-Ares et al. (Madrid: Ministerio de Justicia, 1990), 1972.

3 "Artículo 2341: Responsabilidad extracontractual. El que ha cometido un delito o culpa, que ha inferido daño a otro, es obligado a la indemnización, sin perjuicio de la pena principal que la ley imponga por el delito o culpa cometido." José M. Busto, La antijuridicidad del daño resarcible (Madrid: Tecnos, 1998), 175-203. 
Además de las notas comunes que hemos destacado entre los sistemas de España y Colombia, la doctrina ${ }^{5}$ y la jurisprudencia ${ }^{6}$ coinciden en señalar que los elementos de la responsabilidad civil son (1) hecho generador, (2) daño, (3) nexo causal y (4) fundamento.

Este artículo tiene por objeto elaborar un análisis comparativo en torno a un fenómeno jurídico común de ambos sistemas civiles: causalidad e imputación objetiva. El elemento causal tiene por función determinar quién debe soportar la obligación de indemnizar a la víctima.

La doctrina de la imputación objetiva ha aportado al cambio en la forma de abordar los problemas de causalidad en el derecho de daños, ya que tradicionalmente el juicio de imputación ha sido una suerte de operación implícita que elabora el juez sin tener en cuenta mayores consideraciones teóricas para atribuir un resultado dañoso.

Para cumplir con el objetivo que nos hemos planteado en este trabajo será necesario empezar realizando un breve excurso por las teorías de la causalidad material más conocidas en el ámbito del derecho de daños comparado, con énfasis en España, Colombia y el soft law europeo.

Posteriormente, intentaremos una aproximación conceptual a la noción de imputación objetiva en el ámbito del derecho de daños, exponiendo su origen y describiendo sus postulados. En el siguiente apartado estableceremos diferencias y semejanzas entre la imputación objetiva en derecho penal y de daños.

Luego, analizaremos los criterios de imputación objetiva de acuerdo con el desarrollo teórico construido por la doctrina y la jurisprudencia, valiéndonos de ejemplos para ilustrarlos. Así mismo, se hace un análisis crítico de los criterios contrastados con instituciones tradicionales de la responsabilidad civil.

En el apartado final se analizarán algunas sentencias de la CSJ que aplican o mencionan la imputación objetiva como herramienta para resolver juicios de responsabilidad patrimonial. De esta forma intentaremos dejar planteado un estado del arte de un debate que apenas inicia en el derecho de daños en Colombia. 2008), 329-400 en España; Javier Tamayo. Tratado de responsabilidad civil, tomo I (Bogotá: Legis, 2007), 188-191 en Colombia. 


\section{De la causalidad y sus teorías}

El estudio del fenómeno causal no tiene como origen la disciplina jurídica; ha sido tradicionalmente uno de los temas principales de la filosofía, concretamente de la metafísica u ontología. Desde los presocráticos que buscaban el origen o arjé del cosmos en los elementos de la naturaleza hasta la metafísica de la edad moderna ${ }^{7}$ y la contemporánea teoría de la relatividad.

Kant se ocupó del problema del fin y la causa en la crítica de la razón práctica aludiendo a la experiencia empírica ${ }^{8}$. Esta cuestión también fue abordada por Hegel en su fenomenología del espíritu ${ }^{9}$ y sirvió de fundamento a la teoría de la imputación objetiva formulada por Karl Larenz casi doscientos años después.

En el campo jurídico, el derecho penal es la disciplina que con mayor antigüedad y amplitud ha tratado el problema de la causalidad. En dicho ámbito se ha ido desde la teleología o doctrina de la acción final de Hanz Welzel hasta el funcionalismo de Gunter Jakobs y Claus Roxin ${ }^{10}$.

Con todo, "aunque se puedan seguir encausando los fenómenos del mundo jurídico según la ley causal, sigue habiendo suficientes puntos oscuros [...], es decir, que hasta ahora no hemos logrado aclarar qué es lo que «opera» en la causalidad y cómo sucede; por tanto, sigue habiendo muchos presupuestos no esclarecidos cuando el jurista plantea la sencilla pregunta de si la actuación de un hombre concreto es «causa» de un resultado jurídicamente relevante" ${ }^{11}$.

Las teorías de la causalidad se consideran entonces necesarias mas no suficientes para establecer si una acción puede considerarse causa de un daño dentro del universo de la responsabilidad civil ${ }^{12}$. Sin embargo, como veremos en este trabajo, estas teorías han sido aplicadas en el de daños por la jurisprudencia de España y Colombia.

Friedrich Hegel, Lecciones sobre la historia de la filosofía, t. I (Puerto Rico: Universidad, 1953), 166. Friedrich Hegel, Lecciones, t. III (Puerto Rico: Universidad, 1953), 420.

Friedrich Hegel, Fenomenología del espíritu (Valencia: Pre-textos, 2006), 286.

Santiago Mir, Derecho penal general (Barcelona: Reppertor, 2016), 167.

Claus Roxin, Derecho penal general, I (Madrid: Civitas, 1997), 347.

Jules Coleman, Riesgos y daño (Madrid: Marcial Pons, 2010), 275. Sobre este punto Coleman va más allá y sostiene que tampoco es necesaria puesto que existe responsabilidad sin causalidad. Presenta el ejemplo de quien está obligado a limpiar la nieve de su propiedad y no lo hace; como consecuencia de ello una persona resbala y sufre un daño. 
El elemento imputación responde al siguiente interrogante: ¿Sobre qué patrimonio recaerá la obligación de reparar? No siempre recae sobre la persona que causa materialmente el daño; por tanto, esta pregunta debe orientar todo juicio de imputación y, bajo su tamiz, determinar si los datos que nos proporcionan las teorías de causalidad son suficientes para dar una respuesta.

\section{A) Teoría de la equivalencia de las condiciones y conditio sine qua non}

Todos los hechos que integren un curso causal se consideran condición necesaria para la producción del daño. Este es el postulado principal de la teoría de la equivalencia de las condiciones. Bajo esta tesis, cada acción que compone la cadena causal individualmente considerada aporta a la producción del daño. Se ha considerado que esta teoría es la que mayor cientificidad representa toda vez que acude a criterios físicos o de las leyes naturales para construir un curso causal.

Sin embargo, y en ello radica su principal crítica, bajo esta concepción de la causalidad la responsabilidad patrimonial se extendería de manera infinita buscando la o las causas originarias del daño, lo cual nos ubicaría en el escenario de imputar a los padres por la concepción de un hijo que causó un daño en el presente.

La teoría de la equivalencia bajo esta concepción ortodoxa fue una creación de Julius Glaser. Sin embargo, sería Von Buri quien se encargaría de formular un postulado adicional que adecuara a las necesidades de la disciplina jurídica la mencionada teoría causal ${ }^{13}$. Este postulado se conoce bajo el nombre de conditio sine qua non y consiste en que no es necesario evaluar todas las condiciones que produjeron un daño para establecer cuál es su causa; por el contrario, basta suprimir mentalmente hecho por hecho de la cadena y si al faltar uno de ellos el daño no se hubiere producido, entonces podemos señalarlo como causa.

A pesar del aporte de Von Buri y la acogida de la conditio sine qua non por algunos pandectistas, después de la aparición del BGB esta cedió ante la teoría de la adecuación ${ }^{14}$. La conditio sine qua non aún tiene problemas sin resolver, como, por ejemplo, los daños causados por el miembro indeterminado de un grupo o aquellos en los que concurren varias causas que potencialmente aportan a la producción del resultado dañoso. 


\section{B) Teoría de la causalidad adecuada o de la relevancia jurídica}

Por mucho tiempo, en la jurisprudencia española la denominada teoría de la relevancia jurídica o de la causalidad adecuada fue la herramienta teórica preeminente para establecer la atribución jurídica de un resultado dañoso a un sujeto. En la jurisprudencia colombiana, aún en el presente la teoría de la causalidad adecuada ha prevalecido en la jurisprudencia de la CSJ hasta el año $2016^{[15]}$ en el cual el alto tribunal hizo mención como obiter dicta de la imputación objetiva como elemento de la responsabilidad civil extracontractual en Colombia.

El origen de la teoría de la causalidad adecuada se remonta al siglo XIX, cuando Von Kries la formuló para el derecho penal, y posteriormente, en el siglo XX, Träger la introdujo en el derecho civil ${ }^{16}$. Sostiene que solo pueden considerarse causa de un daño aquellos hechos de la cadena causal que sean relevantes natural y socialmente ${ }^{17}$.

Para establecer cuál es la relevancia jurídica de estos hechos es necesario acudir a juicios de probabilidad; en circunstancias normales, tomando los mismos hechos analizados por un observador experimentado, ¿cuál o cuáles habrían sido las probabilidades que hubiera tenido de evitar el daño?

El maestro Díez-Picazo resume la teoría en dos pasos:

(1) Formación de la descripción del supuesto de hecho: ¿cómo el ideal observador reconstruye los hechos sobre los que debe establecerse la relación causal? La solución de Träger es que la descripción fáctica se elabora a partir de los hechos conocidos y cognoscibles ex ante por un observador ideal ${ }^{18}$.

El anterior postulado ha recibido críticas $^{19}$ debido a que el ideal observador que busca construir la teoría de la causalidad adecuada se asemeja a un dios o sujeto omnisciente; en el ámbito penal, Roxin ${ }^{20}$ ha manifestado que la causalidad adecuada en sí misma es insuficiente como teoría y se trata de un criterio de imputación objetiva.

(2) Juicio de probabilidad del resultado: el juicio de probabilidad "se formula objetivamente tomando en consideración las características uniformes de tipo

CSJ, Cas. Civil, sent. sep. 30/2016, rad. SC13925-2016.

Honoré, "Causation and remoteness", 7-58.

Luis Díez-Picazo, La responsabilidad civil extracontractual (Pamplona: Aranzadi, 2011), 366.

Ídem.

Ídem.

Roxin, Derecho penal, I, 350. 
natural y social que son patrimonio de la cultura y de los conocimientos humanos en el momento en que el susodicho juicio de probabilidad se emite"21.

Así mismo, Mir ha sostenido que la teoría de la adecuación no es una teoría de la causalidad sino un criterio de imputación objetiva cuya función consiste en seleccionar las causas jurídicamente relevantes ${ }^{22}$. Igual postura tiene Larenz en el ámbito del derecho de daños ${ }^{23}$.

La teoría de la causalidad adecuada también puede ser criticada porque no se trata de una herramienta de causalidad sino de previsibilidad, lo cual puede llegar a confundirse con un criterio de atribución de la culpa: la imprudencia. A diferencia de la teoría de la equivalencia, la teoría de la causalidad adecuada se limita a escoger los cursos causales que considera relevantes, subsistiendo así la discrecionalidad absoluta del juzgador y el ya mencionado paradigma del sujeto omnisciente.

\section{C) Teoría de la causa próxima}

La teoría de la causa próxima es la aplicada por la mayor parte de la jurisprudencia angloamericana sobre torts $^{24}$. Al igual que en los sistemas continentales, la doctrina predominante sostiene que la causalidad es uno de los elementos que menos se han teorizado en la doctrina y la jurisprudencia y a la vez el que más problemas representa en cuanto a su aplicación ${ }^{25}$.

Con todo, es bien sabido que el sistema de torts observa algunas diferencias con la mayoría de los sistemas continentales sobre todo en lo atinente a la tipicidad de los hechos generadores de daño y la aplicación del precedente judicial como fuente principal del derecho.

La teoría de la causa próxima viene a ser una aplicación de la conditio sine qua non en conjunto con una amplia discrecionalidad judicial, es decir, se "determina qué actividad es la causa próxima de la ocurrencia de un evento dependiendo de consideraciones de política y de principios" ${ }^{26}$.

Díez-Picazo, Responsabilidad civil, 366.

Mir, Derecho penal general, 170.

Karl Larenz, Derecho Civil Obligaciones, t. I (Madrid: Revista de Derecho Privado, 1958), 199.

Gary Schwartz, "United States. Causation under US law”, en Unification of tort law: causation, editado por Jaap Spier y Francesco Busnelli (Reino Unido: Kluwer Law International, 2000), 123. Con todo, no se debe olvidar la existencia de otros escenarios como el del scope of liability del que hacen eco los PETL.

\section{Coleman, Riesgos y daño, 275.}

Ídem. 
La teoría de la causa próxima consiste en seleccionar un conjunto de condiciones necesarias o contidio sine qua non sin las cuales no se habría producido el daño ${ }^{27}$. No se limita a suprimir solo un evento de la cadena causal para señalarlo como hecho generador, sino que extiende el espectro a un conjunto de condiciones, es decir, la causa puede estar conformada por una o varias actividades que consideradas como un todo constituyen la causa próxima del daño.

Esta teoría se compone de dos pasos: la causa actual y la causa próxima. El primero corresponde a la causa material o física del daño y el segundo a la causa próxima o legal cause. Se afirma que uno de los elementos más importantes para establecer la causa próxima es la previsibilidad del daño ${ }^{28}$.

La causa actual del daño puede ser atribuible al autor, pero si no se logra establecer que le era previsible el daño sufrido por la víctima entonces no será causa próxima del daño ${ }^{29}$. En este postulado encontramos similitudes con la teoría de la causalidad adecuada, la cual también acoge como uno de sus fundamentos la previsibilidad y el hombre promedio.

Si tomamos en consideración que uno de los postulados de esta teoría es que para establecer qué actividades constituyen la causa próxima del daño hay que acudir a cuestiones políticas y de principios, se podría encontrar cierta similitud con la institución de la imputación objetiva.

Uno de los postulados de la teoría de la imputación objetiva consiste en que las personas desarrollan roles en la sociedad frente a los cuales se tiene la expectativa de que dicho desarrollo sea adecuado dentro los límites de riesgo permitido ${ }^{30}$ o siempre que se mantenga el orden normativo ${ }^{31}$.

No es extraño que una teoría causal incluya elementos sociológicos, pues, como ya lo veremos, Larenz encontró el fundamento filosófico de su tesis en Hegel y Jakobs soporta su versión en la sociología de Luhman.

Con todo, la teoría de la causa próxima ha recibido críticas por ser concluyente y no indiciaria ${ }^{32}$; la discrecionalidad judicial es el criterio preponderante para establecer la causa próxima, lo cual ha generado en la doctrina la necesidad de reclamar un examen de causalidad teóricamente más satisfactorio que los de conditio

lbíd., 276.

Schwartz, Causation under US Law, 123.

Ídem.

Roxin, Derecho Penal, I, 379.

Gunter Jakobs, Derecho penal. Parte general (Madrid: Marcial Pons, 1997), 9.

Coleman, Riesgos y daños, 276; y Schwartz, Causation under US Law, 128. 
sine qua non y causa próxima ${ }^{33}$. Aunque la aplicación de esta teoría y sus críticas no son fácilmente reconducibles a los sistemas continentales, no se debe desconocer que el juez está en libertad de aplicar la teoría causal que estima conveniente y por tanto se podrían tomar en consideración los postulados que se consideren útiles.

\section{D) Teorías de la causalidad en el soft law europeo}

El derecho privado de la Unión Europea se divide en comunitario y soft law. El derecho comunitario es de carácter obligatorio para los estados miembros de la UE y está constituido por directivas y reglamentos. El soft law, o normas de derecho blando, también es conocido como derecho académico, y se compone de los trabajos de investigación realizados por diferentes centros de estudio del ámbito continental. Si bien estos trabajos no son de obligatorio acatamiento por parte de los jueces de la UE, la acogida que han tenido como criterio auxiliar o fuente del derecho para resolver casos ha sido prolija ${ }^{34}$.

Existen varios grupos académicos que adelantan trabajos de armonización y unificación del derecho privado europeo. Sin embargo, los que mayor impacto han tenido en la comunidad jurídica europea han sido los Principios de Derecho Europeo de la Responsabilidad Civil (PETL) de la autoría del European Group on Tort Law y el Marco Común de Referencia en contrato y daños (DCFR) elaborado por Research Group on EC Private Law (Acquis Group) \& Study Group on a European Civil Code. Por razones de extensión solo aludiré a los PETL y además porque el DCFR no acoge ninguna teoría de causalidad de las analizadas en este texto, sino que tiene su propio régimen.

Los PETL acogen como teoría de causalidad la conditio sine qua non. Sin embargo, de una lectura detenida de todo el título se puede concluir que no se trata de una aplicación de la conditio sine qua non de la forma tradicional en la que se conoce. El 3:201 de los PETL establece una lista de criterios para determinar el alcance de la responsabilidad, es decir, cuándo una actividad debe ser considerada causa del daño.

Si una actividad es causa en el sentido de la Sección 1 de este capítulo, la cuestión de si puede ser imputada a una persona y en qué medida depende de factores como los siguientes:

34 Antoni Vaquer Aloy, "El soft law europeo en la jurisprudencia española: doce casos", Ars luris Salmanticense 1, n. ${ }^{\circ}$ (2013): 94, https://revistas.usal.es/index.php/ais/article/view/10109. 
(a) la previsibilidad del daño para una persona razonable en el momento de producirse la actividad considerando, en especial, la cercanía en el tiempo y en el espacio entre la actividad dañosa y su consecuencia, o la magnitud del daño en relación con las consecuencias normales de tal actividad;

(b) la naturaleza y valor del interés protegido (artículo 2:102);

(c) el fundamento de la responsabilidad (artículo 1:101);

(d) el alcance de los riesgos ordinarios de la vida; $y$

(e) el fin de protección de la norma que ha sido violada ${ }^{35}$.

Estos criterios guardan similitud con sus homólogos de imputación objetiva y además incluyen otros nuevos, como el fundamento. En cuanto al criterio de previsibilidad, resulta clara la similitud con la teoría de la causalidad adecuada y con el criterio de adecuación. La previsibilidad es uno de los postulados expuestos por Träger para fundamentar su teoría.

El criterio de naturaleza y valor del interés protegido incluye elementos subjetivos al proceso de imputación y hay que decir que no está claro cómo puede influir el interés en la imputación de un daño ya que la vulneración de un derecho ajeno no es por sí misma una fuente de responsabilidad y menos un criterio para establecer si una actividad de la cadena causal es la generadora del daño.

En lo que hace al fundamento, pareciera que el sistema de causalidad de los PETL cambia de acuerdo con la actividad desarrollada por el autor. Por ejemplo, una actividad riesgosa será valorada de forma más estricta que una que no lo es; de hecho, el artículo 1:101 establece pautas para identificar una actividad riesgosa y enuncia algunos deberes de comportamiento en tales situaciones. No obstante, considero que incluir el fundamento como criterio para determinar si una actividad es causa o no lo es, es embeber el juicio de fundamento en el de imputación como si fuera una sola categoría jurídica y no dos diferentes.

Finalmente, aparece el criterio de protección de la norma el cual también es tal en la teoría de la imputación objetiva. Se debe tomar en consideración, más allá de la relación causa-efecto, si el agente actuó fuera del ámbito de protección de la norma. No es un criterio de fundamento ${ }^{36}$, como podría pensarse, sino, más bien, de relevancia jurídica de la actividad dentro de la cadena causal.

Principios europeos de responsabilidad civil (PETL). Traducción de Miquel Martin-Casals, http:// www.egtl.org/PETLSpanish.html.

36 Cuando hablo de fundamentos aludo a la imputación jurídica, juicio de reproche, imputación subjetiva. Considero que la RC se compone de tres elementos: daño, imputación o nexo causal y fundamentos. Sobre este punto en Colombia, Saúl Uribe, "El caos dogmático en la responsabilidad en la responsabilidad civil” en Responsabilidad civil y del Estado n. ${ }^{\circ} 20$ (Medellín: IARCE, 2006), ha señalado el baile dogmático sobre los elementos de la RC; en el derecho administrativo Héctor 
Con un ejemplo podemos ilustrarlo: En la ciudad $X$ existe una norma que prohíbe la circulación de motocicletas los días 30 y 31 de cada mes. Juan conduce su motocicleta un día 30 en la ciudad X, desarrollando la actividad de manera correcta cuando un autobús que desobedece la señal de alto, lo atropella y causa lesiones. El conductor del bus no podría alegar que la causa del daño fue que Juan sacó su moto en un día prohibido, pues el fin de protección de esa norma es descongestionar el tráfico, lo cual está fuera de la órbita del accidente ejemplificado. Volveremos sobre este criterio cuando abordemos la imputación objetiva.

Para terminar con esta parte, considero importante poner de presente que la conditio sine qua non bajo la versión de los PETL guarda muchas similitudes con la teoría de la causa próxima y la de la imputación objetiva. Esto es una respuesta a la conciliación en el texto de varias familias jurídicas que integran la UE tanto las que descienden del common law como las del sistema continental, que, como bien se sabe, guardan diferencias entre sí; basta contrastar los sistemas derivados del BGB (Alemania, Portugal y parcialmente Italia) y los que tienen como tronco común el Code de 1804 (Francia, España y la mayor parte de América Latina, teniendo en cuenta la influencia del BGB en Brasil y el nuevo código de derecho privado argentino que bebe de varias fuentes).

\section{Imputación objetiva en el derecho de daños}

Kant, en su metafísica de las costumbres, había desarrollado un pensamiento ético alrededor de la razón como elemento principal para distinguir lo justo de lo injusto $^{37}$. Tiempo después, Hegel a través de su obra criticó a Kant y propuso como criterio de distinción de lo justo la voluntad del sujeto en lugar de la razón pura.

Este planteamiento de Hegel fue acogido por Karl Larenz, pero con una variación: “[...] considera que la relación con la voluntad no es una relación subjetiva que solo pueda establecerse con lo que el sujeto se ha representado, sino que es

Patiño lo ha puesto de presente en "El bípode o el trípode: la estructura de la responsabilidad", en Responsabilidad extracontractual del Estado: ¿qué?, ¿por qué?, ¿hasta dónde?, editado por Juan Henao y Andrés Ospina (Bogotá: Universidad Externado de Colombia, 2015). Aclaro este punto dado que algunos autores consideran que la imputación objetiva y sus criterios son más bien subjetivos y puede haber confusión en el hecho de fusionar la imputación y el fundamento. Además, lo llamo fundamento porque no siempre hay un juicio de reproche y lo concibo una categoría más incluyente respecto de las teorías que existen al respecto. 
una relación objetiva que se establece igualmente con lo que el sujeto podía haberse representado, pues la «posibilidad de previsión»"38.

La imputación objetiva tiene por función limitar las consecuencias jurídicas de la causalidad natural considerando adecuadas solo aquellas que son relevantes para responsabilidad civil. Es importante resaltar que no se prescinde de la causa material, sino que se establecen criterios (reglas) para determinar si un daño es objetivamente imputable a un sujeto de acuerdo con el derecho de daños.

La imputación objetiva es considerada mayoritariamente una creación de Larenz, pero su mayor desarrollo ha ido de la mano del derecho penal y los representantes del funcionalismo. La tesis original de Larenz consiste en una lectura diferente de la teoría de la adecuación al no considerarla una teoría de la causalidad sino una herramienta o criterio para escoger los hechos jurídicamente relevantes de un curso causal. Los criterios de imputación objetiva que conocemos fueron creados después, y solo el de adecuación fue abordado expresamente por Larenz en su obra ${ }^{39}$.

Con todo, el abordaje del criterio de adecuación fue base suficiente para el desarrollo de la teoría de la imputación objetiva, puesto que además de limitar la causalidad material en el ámbito del derecho de daños, dejó claramente trazadas las fronteras entre la imputación y el reproche subjetivo atinente al fundamento; se trata de dos elementos claramente diferenciados en la doctrina de Larenz, lo cual es de un impacto ingente en sistemas tanto abiertos como cerrados, ya que se desecha la antijuridicidad como elemento de la imputación y la circunscribe al ámbito del daño y el fundamento.

Sobre este punto enseña el maestro:

Al responsable del hecho solamente le pueden ser imputadas y tenidas en cuenta en la determinación del daño aquellas consecuencias "adecuadas" al hecho generador de la responsabilidad. Se trata, por consiguiente, de una imputación objetiva de las consecuencias producidas, no de una imputación subjetiva a título de culpa. La sentencia que declara adecuado un efecto al hecho base de la responsabilidad y por ello declara que el agente ha de responder de él, no contiene reproche alguno de culpa ${ }^{40}$.

Mario Maraver Gómez, "Consideraciones sobre la teoría de la imputación objetiva", en Anuario de Derecho Civil (2010): 337. al presentar el ejemplo de la persona que toma un vuelo retrasado y sufre un daño por un sujeto diferente a la aerolínea. 
La anterior cita también resulta importante para justificar la pertinencia del análisis comparativo de la imputación en los sistemas abiertos y cerrados. Aunque los elementos daño y fundamento guarden notables diferencias en los sistemas derivados del BGB y los abiertos, en materia de imputación no puede decirse lo mismo. La antijuridicidad y la culpa están excluidas del proceso de imputación en ambos sistemas, por tanto, es posible establecer un paralelo ${ }^{41}$.

En obediencia a esta similitud Pantaleón introdujo el concepto de imputación objetiva en el derecho civil español. En los sistemas civiles de cláusula general no se califican los elementos de la responsabilidad, sino que estos se extraen a partir de la descripción normativa.

En primer lugar, la cláusula general de responsabilidad no indica cuál es la teoría de causalidad que se debe aplicar para la atribución de daños. Esto ha sido una creación jurisprudencial, por lo cual Pantaleón parte del análisis de la jurisprudencia española y el derecho de daños alemán para proponer su teoría de la imputación objetiva en el derecho civil español.

Ya en su tesis doctoral Pantaleón había iniciado su trabajo comparativo entre el derecho civil alemán y español cuando disertó sobre el concepto de daño y la ausencia de antijuridicidad en el derecho de daños español ${ }^{42}$. Este ejercicio es de gran valor para los avances de la responsabilidad civil en los sistemas abiertos pues es bien conocida la rivalidad intelectual entre franceses y alemanes, lo cual ha impedido trasladar institutos de un sistema a otro. No en vano Markesinis ${ }^{43}$ comenta de forma jocosa que los franceses, parafraseando a Voltaire, dicen que la causalidad es una invención de algún jurista alemán.

El mérito de Pantaleón consiste en conciliar los aspectos dogmáticos del derecho de daños alemán y español en las materias que es posible, sin dejar de lado las diferencias que separan ambos sistemas. Así las cosas, considera que la imputación objetiva, insistimos, no viene a eliminar la causalidad material o natural sino a condicionarla. De igual forma es menester resaltar que Pantaleón no considera que la imputación objetiva sea una suerte de cajón de sastre para solucionar todos los problemas de causalidad; todo lo contrario, cree que son criterios útiles pero que en manera alguna son nuevas categorías dogmáticas inmutables y axiomáticas ${ }^{44}$.

Fernando Pantaleón, "Causalidad e imputación objetiva: criterios de imputación", en Centenario del código civil 1889-1989, t. II (Madrid: Ramón Areces, 1990), 1580. Sobre este punto sostiene que la antijuridicidad no opera en la imputación, aunque existan algunos autores que consideren que lo contrario; por todos Busto, La antijuridicidad del daño, 175. de Madrid, tesis inédita, 1990), 398. 


\section{Breve excurso por las diferencias entre la imputación objetiva penal y la civil}

La imputación objetiva en derecho penal consiste en verificar la realización del tipo objetivo, la cual por sí sola no es suficiente para establecer la responsabilidad penal; es necesario también analizar el tipo subjetivo ${ }^{45}$. Algo similar ocurre en derecho civil, aunque con algunas diferencias. En primer lugar, los sistemas civiles abiertos, como los de España y Colombia, son atípicos, es decir, no es necesaria la comisión de una conducta descrita en la ley para el surgimiento de responsabilidad civil, así como tampoco hay una norma que establezca cuáles son los daños resarcibles ${ }^{46}$. Esto es impensable en la responsabilidad penal ya que la tipicidad y la legalidad son dogmas invariables por razones de seguridad jurídica del procesado.

La segunda cuestión es la antijuridicidad; en los sistemas abiertos no existe la antijuridicidad, mientras que en el derecho penal es una constante que no se puede soslayar ${ }^{47}$. La imputación objetiva en el derecho de daños tiene la función de establecer si los hechos analizados son o no jurídicamente relevantes para el universo de la responsabilidad civil, es decir, cuáles conductas de la cadena causal pueden ser consideradas tal y cuáles no. Al igual que en el derecho penal, el juicio de reproche se reserva para otro elemento diferente, pues en éste se lleva a cabo en el tipo subjetivo, y en derecho civil, en el análisis de fundamentos, esto es, si el agente debe responder por culpa, riesgo $u$ otro.

En Colombia el profesor Yesid Reyes da cuenta de esta diferencia cuando alude a la determinación del riesgo desaprobado. De acuerdo con el concepto de adecuación social, se plantea que es necesario ponderar los intereses en juego para establecer si existe una desaprobación social ${ }^{48}$. Se plantea si son los factores individuales o sociales los que se deben tener en cuenta para establecer el riesgo. Con todo, no se aparta de la noción de antijuridicidad, ya que es un contrasentido en

Jakobs, Derecho penal, 190.

Con todo en la jurisprudencia colombiana se han presentado sentencias en donde se invoca la antijuridicidad del daño, mas no de la conducta. Aludimos a las sentencias de la CSJ, Sala de Casación Civil, del 18 de diciembre de 2010, rad. SC5686-2018, y el 29 de abril de 2016, rad. SC5516-2016. No compartimos esta posición y nos suscribimos a la tesis de Fernando Pantaleón (El concepto de daño), en la que se sostiene que en los sistemas de responsabilidad de atípicos o de cláusula general, cualquier interés es susceptible de tutela salvo que se oponga otro interés más fuerte o devenga en ilícito. Lo anterior sin desconocer el principio de entidad mínima del daño.

Mir, Derecho penal general, 169, sostiene que "la tipicidad es la base de la antijuridicidad penal".

Yesid Reyes, Imputación objetiva (Bogotá: Temis, 1994), 108. 
la dogmática penal y por ende considera que "la ponderación de intereses debería hacerse de forma independiente con cada tipo penal" 49 , esto es, la conducta ha de ser típica para ser evaluada, cosa que no acontece en el ámbito civil, donde cualquier interés es susceptible de tutela salvo que se oponga otro más fuerte o devenga en ilícito.

Adicionalmente, siguiendo a Juan A. García, señalamos dos diferencias más: (1) en la responsabilidad civil el protagonista es la víctima y su daño, mientras que en el derecho penal es el sujeto y su conducta; (2) el derecho de daños se basa en la asignación de costes del daño, distribuidos entre el autor, terceros y la víctima, mientras que en el derecho penal es inviable ya que quien lesiona o pone en peligro un bien jurídico tutelado recibe una pena; en el derecho de daños la función es compensar; en el penal, castigar y prevenir ${ }^{50}$.

\section{Criterios de imputación objetiva en el derecho de daños. Jurisprudencia española}

Los criterios de imputación objetiva son útiles tanto para impedir como para formular la atribución de un daño. Estos pueden aplicarse de forma alternativa y no necesariamente conjuntiva; además, un caso puede resolverse aplicando uno o varios criterios, pues su función consiste en limitar la causalidad material ${ }^{51}$.

También nos suscribimos a la idea del maestro R. de Ángel, quien preconiza la vigencia de las clásicas teorías y fórmulas de causalidad material, es decir, la imputación objetiva no viene a eliminar o sustituir los avances en materia de causalidad, sino a complementarlos o servir de alternativa para la solución de $\operatorname{casos}^{52}$.

Hemos sido reiterativos en señalar que la imputación objetiva busca limitar la causalidad material, de lo cual surge la siguiente pregunta: ¿Cuál es la teoría de causalidad que se busca limitar de acuerdo con su impacto en el universo jurídico?, respuesta: la teoría de la equivalencia de las condiciones.

\footnotetext{
49 Ídem.

50 Juan A. García, "Sobre algunos mitos del derecho de daños", en Derecho de daños, dirigido por Mariano Herrador (Cizur Menor, Aranzadi, 2013), 98.

51 Pantaleón, Causalidad e imputación, 1592.

52 Ricardo de Ángel, Causalidad en la responsabilidad extracontractual (Pamplona: Civitas, 2014), 221.
} 
En el derecho penal Jakobs y Roxin, desarrolladores del concepto contemporáneo de imputación objetiva, sostienen que ha de partirse de la teoría de la equivalencia de las condiciones puesto que es la única que ofrece cientificidad y certeza ${ }^{53}$. Este fue uno de los planteamientos principales de Pantaleón al proponer aplicar en el derecho de daños la imputación objetiva penal, como lo hiciera, en ese entonces, la Sala Segunda del Tribunal Supremo español.

Pantaleón afirma que "el derecho no puede sino partir del concepto de causalidad propio de la Lógica y de las ciencias de la naturaleza: la llamada «concepción nomológico funcional» de la causalidad"54. Como ya vimos, en los sistemas de common law también se aplica la teoría de la equivalencia de las condiciones, pero bajo la forma de conditio sine qua non.

A pesar de que la teoría de la adecuación, bajo sus diferentes lecturas, ha sido la predominante en los sistemas civiles continentales, ninguno de los textos de soft law en materia de daños la acoge como sistema. En España desde los años noventa la jurisprudencia ha acogido la imputación objetiva, aunque no sin excepciones y bajo lecturas muy diversas.

Esta aproximación conceptual nos conduce a identificar la teoría de la equivalencia como punto de partida de los criterios de imputación objetiva; es el elemento fáctico o material, al que se le busca un límite jurídico el cual está demarcado por los criterios de imputación objetiva.

Finalmente, es necesario advertir que no existe un total consenso sobre los criterios de imputación objetiva en el derecho de daños. No se trata de un catálogo cerrado de criterios, pues pueden surgir otros nuevos o trasladar otros del derecho penal, como ha propuesto Juan A. García con el dominio del hecho. Así pues, puede que se echen de menos algunos criterios abordados por otros autores y se hayan agregado algunos nuevos.

\section{A) Criterio de adecuación}

Informa Honoré que este criterio ha sido el que con más detalle se ha estudiado en la doctrina y la jurisprudencia y ha sido acogido en sistemas de derecho civil atípicos y típicos ${ }^{55}$. 
La causalidad adecuada no es una teoría causal porque no se basa en las leyes de la naturaleza sino en las leyes del pensamiento humano en el contexto del marco teórico del derecho de daños; valiéndonos de ella no podemos establecer relaciones de causa a efecto ni explicar el curso de una cadena causal. Tal como anota Pantaleón, "los operadores jurídicos no son «productores», sino «consumidores» de las leyes causales"56.

En el acápite B, "Teoría de la causalidad adecuada o de la relevancia jurídica”, de este escrito, la teoría de la causalidad adecuada se basa en dos elementos: (1) formación de la descripción del supuesto de hecho y (2) juicios de probabilidad. Líneas atrás este criterio fue expuesto como la teoría que se formuló originalmente, pero en este acápite desarrollaremos elementos adicionales que obedecen a su ubicación sistemática como criterio de imputación objetiva o como teoría autónoma de la causalidad.

La formación de la descripción del supuesto de hecho es explicada por Larenz de la siguiente manera:

No interesa el conocimiento y previsión personal del responsable del daño, sino la apreciación hecha según la experiencia media de un juzgador u observador perspicaz, para el que, en el momento de ocurrir el hecho generador de la responsabilidad, fueran cognoscibles ya todas las circunstancias, y no solamente las que sean notorias (el denominado pronóstico objetivo ulterior) ${ }^{57}$.

Se trata de un elemento empírico en virtud del cual se acude al estándar del observador ideal. Sin embargo, el marco normativo de cada actividad puede proporcionar datos al observador que le permitan determinar cuáles eran los hechos conocidos y cognoscibles ex ante; por ejemplo, si se trata de una cirugía el médico está en la obligación de informar los riesgos propios del procedimiento al paciente; el observador ideal tomará como conocida o cognoscible esta circunstancia, aunque el médico niegue conocer esa obligación.

Ahora bien: en este caso el deber de información nos proporciona datos para construir el supuesto de hecho, pero solo son útiles para el juicio de imputación, ya que, como es sabido, puede haber imputación pero ausencia de fundamento y por lo tanto no surgir la obligación de reparar.

En cuanto al juicio de probabilidad del resultado: La probabilidad no se construye únicamente con las reglas de la naturaleza y la experiencia, sino que se acude 
al ordenamiento jurídico para verificar los roles de cada sujeto en la actividad que se desarrolla, no para establecer cumplimiento o no de deberes de comportamiento sino para determinar el margen de acción de la actividad en cuestión. No se pierda de vista que en este punto aludimos a la adecuación como criterio de imputación objetiva, no como teoría de la causalidad; por tanto, el criterio de relevancia no va unido solamente a los juicios de probabilidad en su faceta probatoria, sino como un elemento demarcatorio de las normas jurídicas ${ }^{58} \mathrm{y}$ de la experiencia que ayudan a elegir cursos causales.

En este sentido, el criterio de adecuación y en general la imputación objetiva limitan el principio de libertad ex ante bajo la creación de los roles que cada sujeto desarrolla que se enmarcan en normas jurídicas o empíricas, dependiendo de la actividad a que se refiera ${ }^{59}$. Por ejemplo, las normas de tráfico nos indican el rol del peatón y el del conductor y aunque se trate de un evento de responsabilidad en el que no haya mediado culpa, se verifica el cumplimiento del rol para escoger las causas que se consideren adecuadas para el mundo jurídico.

En un trabajo anterior sin publicar propusimos otro ejemplo ${ }^{60}$; para establecer quién o quiénes deben responder en los juicios por privación injusta de la libertad bajo la Ley 906 de 2004 en Colombia, el juez debe acudir al Código Penal y al de Procedimiento Penal para verificar los roles de cada uno en el proceso. En esta etapa no se constata el cumplimiento de deberes de comportamiento, pues puede que en la etapa de la imputación jurídica o fundamento se escoja uno objetivo (daño especial) o uno subjetivo (falla del servicio); lo que se quiere verificar es qué actuaciones de cada sujeto constituyen causa adecuada del daño y como consecuencia quién y en qué porcentaje está obligado a reparar.

Elegimos iniciar el análisis de los criterios con el de adecuación porque fue en el que se basó Larenz para formular la imputación objetiva y además debido a que ha sido el más estudiado bien sea como criterio o como teoría. Sin embargo, en la propuesta de Pantaleón para el derecho civil este criterio aparece como subsidiario; es decir, si no es posible resolver un caso aplicando otros criterios, entonces es viable acudir al viejo criterio de la adecuación ${ }^{61}$.

En este sentido Reyes, Imputación objetiva, 117: “[L]a desaprobación de un riesgo depende de una ponderación entre la conducta efectivamente desarrollada y aquella que debería haberse desplegado para la evitación del resultado, no es necesariamente el cumplimiento de determinada reglamentación lo que indica que se actuó conforme a un deber".

59 Roxin, Derecho Penal, I, 350.

60 Eduardo Sirtori, Responsabilidad por privación injusta de la libertad (trabajo sin publicar).

61 Pantaleón, Causalidad e imputación, 1561. 


\section{B) Prohibición de regreso}

En los comentarios preliminares fijábamos como punto de partida la teoría de la equivalencia de las condiciones. El criterio de prohibición de regreso establece límites a la extensión de la responsabilidad excluyendo como causa las actividades de la cadena que sean consideradas consecuencias muy alejadas gracias a la realización del hecho de un tercero que cumpla con los requisitos para ser causa del daño.

El maestro De Ángel lo explica así:

En estos casos se habla de "prohibición de regreso», para expresar la idea de que, en la imputación objetiva, no se puede «regresar» desde el tercero que dolosa o culposamente intervino causando el daño hasta el que desencadenó el curso causal, por más que hubiera sido condición sine qua non del daño ${ }^{62}$.

En la jurisprudencia española el caso del Hotel Corona de Aragón tradicionalmente ha servido de modelo para explicar este criterio. Sin embargo, en un pronunciamiento más reciente el TSE ${ }^{63}$ volvió a analizar el criterio de prohibición de regreso y la doctrina de la imputación objetiva en el derecho de daños.

La empresa Endesa pretendía que se declarara la responsabilidad patrimonial de Red Eléctrica de España (REE) como consecuencia de los perjuicios sufridos por la primera a causa de un incendio en una estación eléctrica en Barcelona.

REE era la responsable del mantenimiento de las redes eléctricas de voltaje 220, y Endesa, de las correspondientes al voltaje de 110. Los cables de 110, pertenecientes a Endesa, se desprendieron y cayeron sobre los cables de 220, que se encontraban en mal estado. La suma de ambos hechos produjo el incendio. Así lo consideró el Tribunal de instancia y el TSE en la sentencia comentada.

Endesa pretendía que se aplicara el criterio de prohibición de regreso alegando que la causa próxima del daño era exclusivamente el mal estado de los cables de la REE y como consecuencia su actividad en la cadena no debía ser considerada causa.

EI TSE desestimó este argumento y sostuvo:

[...] el factor desencadenante del siniestro se encuentra en la caída de los cables de $110 \mathrm{KV}$ de Endesa, por lo que difícilmente puede pretender que no le incumba ninguna responsabilidad acudiendo al criterio de la prohibición de regreso. Existe una conducta imprudente de REE en la conservación y mantenimiento de los cables de 
ella, que propicia el incendio, pero este se ha visto favorecido, de manera próxima y no remota, por la imprudencia de Endesa en la conservación y mantenimiento del cable de $110 \mathrm{KV}$, y en el contacto entre ambos cables, debido a la defectuosa y poco previsible instalación de los cables sobrevolando uno al otro. De ahí, que no quepa considerar infringida, dentro de la causalidad, la tesis de la imputación objetiva, al sentar la sentencia recurrida que la conducta negligente de Endesa ha de calificarse como una causalidad contributiva que ha favorecido decisivamente la causación final del siniestro ${ }^{64}$.

Esta sentencia reitera la aplicación uniforme del TSE sobre la doctrina de la imputación objetiva reseñando pronunciamientos de finales de los noventa hasta la sentencia número 147/2014, del 18 de marzo.

Ahora bien: este criterio nos lleva a preguntarnos cuál es la diferencia entre la prohibición de regreso y la causal eximente que tradicionalmente se conoce como hecho de un tercero. ¿Acaso no es la misma noción de tercero en virtud de la cual el sujeto debe ser ajeno al juicio de responsabilidad y sobre el cual no se tiene una relación especial de sujeción o posición de garante?

Creo que podemos extraer por lo menos dos notables similitudes: (a) la noción de hecho de un tercero consiste en que el causante directo del daño es un tercero ajeno a las partes intervinientes en el juicio de responsabilidad ${ }^{65}$; (b) tanto eximente como criterio tienen su operatividad en el momento de la imputación; el hecho de un tercero impide la imputación y el criterio de prohibición de regreso la excluye, por lo cual los efectos son los mismos.

\section{C) Riesgo general de la vida}

Para el maestro Díez-Picazo, este criterio consiste en que

Si el curso causal que conduce al resultado lesivo o dañoso ha sido puesto en marcha por un autor mediato, pero en él, posteriormente, han intervenido acciones de terceros que resultan modos de actualización de un riesgo habitualmente ligado a la existencia natural del dañado o a los que se desencadenan en la existencia humana en la forma de socialización y civilización correspondiente, no se deben imputar los daños a ese autor mediato ${ }^{66}$.

TSE, Sala 2. ${ }^{\text {a }}$, sent. feb. 24/2017, rad. 717/2017, 15. Privado, n. ${ }^{\circ} 14$ (2008), 207. 
Tradicionalmente se ha ilustrado este criterio con este ejemplo: el autor de heridas leves no es responsable de las lesiones padecidas por la víctima en un hecho de circulación cuando salía del hospital. Parte del postulado de Jakobs de que la vida en sociedad implica riesgos y que lo que el ordenamiento jurídico quiere no es limitar los comportamientos en la sociedad sino mandar un mensaje de vigencia de la norma cuando hay un comportamiento que quebranta la confianza puesta en un rol ${ }^{67}$.

Todos debemos soportar ciertas molestias y riesgos mínimos que conlleva la vida en sociedad, lo cual se manifiesta en que en ocasiones debemos soportar el daño padecido por ser un riesgo general de la vida.

En el ámbito civil el TSE ha aplicado este criterio en repetidas ocasiones en asuntos derivados de caídas en establecimientos públicos. En un primer proceso, no acogió las pretensiones en un caso en el que el demandante sufrió una caída como consecuencia de una manguera extendida en el piso para regar el jardín ${ }^{68}$. En otro caso, consideró que la caída de la demandante en un mercado fruto del suelo mojado por la lluvia responde a riesgos generales de la vida y por tanto no son imputables objetivamente al demandado ${ }^{69}$.

En las audiencias provinciales (AP) también se ha aplicado el criterio de riesgo general de la vida. La AP de Alicante lo aplicó para impedir la imputación objetiva de "las lesiones sufridas por un invitado al caer en el baño de una casa tras resbalar con el agua jabonosa que dejó un hijo de los propietarios al lavarse las manos"70. A su vez, la AP de Almería sostuvo que la caída fruto del tropiezo con un escalón señalizado en un establecimiento público es consecuencia del riesgo general de la vida ${ }^{71}$.

De acuerdo con esta línea jurisprudencial, es posible afirmar que el criterio de riesgo general de la vida toma en especial consideración la previsibilidad del hecho para la víctima y que no se haya tratado de un descuido de esta. Así lo estiman las decisiones reseñadas, en las cuales se le asigna la previsibilidad a la víctima y no al autor.

Sin embargo, la forma de razonar de la AP de Santa Cruz de Tenerife es diferente: decidió que no era aplicable el riesgo general de la vida cuando la circunstancia es previsible para el autor. El demandante sufrió una caída en el restaurante

\footnotetext{
67 Jakobs, Derecho penal, 243.

68 TSE, Sala 1. ${ }^{a}$, sent. mar. 2/2006, rad. 194/2006.

69 TSE, Sala $1 .^{\text {a }}$, sent. feb. 22/2017, rad. 149/2007.

70 AP de Alicante, sección novena, sentencia 219/2017 del 15 de mayo de 2017

71 AP de Almería, sección tercera, sentencia 133/2014 del 30 de julio de 2014.
} 
de un hotel por haber pisado restos de comida que se encontraban en el suelo ${ }^{72}$. También el TSE cuando consideró que no era aplicable este criterio en un caso en el que el demandado fallece al caer por una pendiente sin señalizar en la que se encontraban exhibidos unos vehículos para su venta ${ }^{73}$.

\section{D) Riesgo permitido e incremento del riesgo}

Jakobs plantea que la vida en sociedad implica riesgos. Todos como elementos de la sociedad somos portadores de un rol, el cual a su vez genera unas expectativas legítimas en los demás. Existe un alea de riesgo permitido la cual está determinada por el rol de cada sujeto; si se sobrepasa, entonces el resultado dañoso le será objetivamente imputable ${ }^{74}$.

El criterio de riesgo permitido es el género de otras manifestaciones como el principio de confianza, en virtud del cual, "a pesar de la experiencia de que otras personas cometen errores, se autoriza a confiar -en una medida aún por determinar- en su comportamiento correcto) entendiéndolo no como suceso psíquico, sino como estar permitido confiar)" 175 .

Se entiende, entonces, que existen unas expectativas de comportamiento razonables dadas por unos roles, los cuales a su vez indican el espectro de riesgo permitido. Jakobs explica este criterio con un ejemplo:

[...] todo fabricante de vehículos automóviles (aunque lo haga correctamente) es causante, por la fabricación, de todos los accidentes en que intervenga un vehículo suyo, sin que la fabricación se convierta por ello en un suceso que sea tolerable solo en relación con un contexto jurídico del fabricante ${ }^{76}$.

EI TSE aplicó este criterio al considerar que hubo incremento del riesgo por parte de una estación de esquí al instalar un cañón dispensador de nieve en la pista:

Es un hecho acreditado que instaló un cañón de nieve en un lugar próximo a la pista, lo que, indudablemente, incrementa el riesgo inherente a la propia práctica del esquí. Y de igual forma es acertado concluir que resultaba previsible que contra

AP de Santa Cruz de Tenerife, sección tercera, sentencia 416/2017 del 24 de noviembre de 2017. 
dicho elemento colisionaran los esquiadores en caso de las también previsibles, por habituales, caídas durante la práctica de este deporte, aún sin mediar culpa alguna del deportista, como fue el caso. Con esos datos, debe juzgarse como razonable la decisión de calificar como no diligente la conducta de la empresa titular de la estación pues, como en el caso mencionado del organizador de una carrera ciclista, el dueño de una estación de esquí se encuentra obligado a poner los medios adecuados para evitar el daño teniendo en cuenta la naturaleza de la actividad que gestiona, y con mayor motivo, cuando contribuyó a incrementar el riesgo propio de la actividad deportiva colocando en un lugar próximo a la pista un elemento artificial, rígido y duro, como un cañón artificial, que generaba riesgo evidente de lesiones en caso de colisión, incluso si esta se producía por consecuencia de un deslizamiento subsiguiente a una caída. Y siendo todo ello previsible, las caídas, las colisiones y el daño, no podía limitarse a señalizar el elemento, sino que le incumbía adoptar medidas encaminadas a evitar o disminuir el riesgo de lesiones, lo que no hizo (el colchón naranja, por sus características - groso insuficiente- no servía para preservar la integridad de los esquiadores en caso de impacto) ${ }^{77}$.

En la doctrina española a este criterio también se le ha denominado conducta alternativa correcta, y consiste en "descartar la imputación en supuestos en los que se ha determinado que un resultado sustancialmente idéntico se hubiera producido de haber obrado el agente con toda diligencia"78.

No obstante que el TSE se vale del criterio del incremento del riesgo para resolver el caso, es evidente que aplica criterios subjetivos de imputación. En el aparte citado se habla de negligencia y previsión y da la sensación de que nos trasladamos al terreno de la culpa. Esta apreciación encuentra respaldo en el pensamiento de Regleros, quien estima que los criterios de imputación objetiva no son más que la aplicación de los tradicionales factores de atributivos de culpa ${ }^{79}$.

Así mismo, el maestro Montés estima que algunos criterios de imputación objetiva, entre ellos incremento del riesgo, se aplican en la jurisprudencia, pero bajo otra denominación ${ }^{80}$, por lo cual no es extraño el razonamiento del TSE en la sentencia citada.

TSE, Sala 1. ${ }^{\text {a }}$, sent. feb. 9/2011, rad. 64/2011.

Vicente Montés, “Causalidad, imputación objetiva y culpa”, en Estudios jurídicos en homenaje al profesor Luis Díez-Picazo, t. II, coordinado por Antonio Cabanillas (Madrid: Thomson, 2003), 2606.

Luis Regleros, Tratado de responsabilidad civil, t. I (Cizur Menor: Aranzadi, 2008), 733.

Montés, Causalidad, imputación objetiva y culpa, 2606. 


\section{E) Fin de protección de la norma}

Afirma Jakobs que el derecho no busca regular el comportamiento humano "simplemente porque sí, sino para posibilitar la vida en sociedad"81. Las normas jurídicas imponen deberes de comportamiento para cada sujeto de acuerdo con su rol; para cumplir con dicho fin, las normas persiguen un objeto o fin el cual debe determinarse en relación con la relevancia causal que tenga el incumplimiento de estas.

Dicho de otra forma: el incumplimiento de una norma de conducta por sí solo no permite la imputación objetiva de un daño. Es necesario que la violación al contenido obligacional guarde relación con el fin de protección de la norma, el cual generalmente se relaciona con los bienes jurídicos que ésta busca tutelar. Sin embargo, hemos de recordar que el derecho de daños bajo los sistemas abiertos no exige la antijuridicidad como elemento del daño, por tanto, no es necesario que la norma de forma expresa indique cuál es el bien jurídico vulnerado, pues, como sostiene Pantaleón. Basta alegar un interés el cual sólo tiene como límite la ilicitud de este o la oposición de otro interés más fuerte ${ }^{82}$.

No todas las normas tienen claro cuál es su finalidad y tampoco buscan siempre la protección de un bien jurídico. Existen normas de recaudo y control administrativo cuya violación no apareja necesariamente la imputación del daño ${ }^{83}$.

Alguien puede haber violado una norma y haber cometido una culpa, pero no necesariamente esta conducta será objetivamente imputable. Presentamos dos ejemplos: (1) la CSJ no encontró un nexo de causalidad entre el actuar negligente del personal médico al momento de diligenciar la historia clínica (violación a una norma de conducta) y el fallecimiento de un paciente como consecuencia de una hemorragia posterior a una cirugía.

Así ha fallado la CSJ:

[...] pero, en tratándose de una deficiente o inexacta inscripción de datos referidos al paciente en cuestión, la demostración de tal falencia podrá servir de indicio para la formación de convencimiento acerca de la responsabilidad investigada, sin que en principio pueda concluirse, en sede de casación, que la adecuada demostración de un error probatorio como el que se le atribuye al Tribunal en este caso pueda conducir, sin más, a deducir la obligación de resarcir los perjuicios reclamados ${ }^{84}$.

Pantaleón, Concepto de daño, 400.

Pantaleón, Causalidad e imputación, 1587.

CSJ, Cas. Civil, sent. mar 2/2016, rad. SC2506-2016, 45. 
(2) El depósito de basuras en la ciudad $Y$ se realiza en el horario de 19 a 21 horas. Una persona deposita basura en un contenedor y resulta lesionada como consecuencia de un defecto en la tapa, la cual le cayó encima. El hecho ocurrió a las 18:30 horas.

La empresa responsable no puede alegar como eximente que el hecho ocurrió fuera del horario de depósito por dos razones: (a) el fin de protección de esa norma es mantener el orden y salubridad pública depositando la basura en forma organizada; también obedece a las rutas de los camiones que recogen los contenedores, o sea razones técnicas y administrativas; la norma no tiene la finalidad de prevenir accidentes; (b) el hecho habría ocurrido tanto en el horario de depósito como fuera de él, luego este criterio, combinado con el de incremento de riesgo, permite concluir que el defecto de la tapa del contenedor no le era previsible a la víctima ni a las 19 ni a las 18:30 horas.

Este criterio también puede aplicarse junto con el de prohibición de regreso o el de adecuación. Por ejemplo, en el caso del médico que rellenó negligentemente la historia clínica, el criterio de adecuación sirve para excluir ese hecho de la cadena por no tener relevancia jurídica. De igual manera, se podría combinar con la prohibición de regreso pues una vez identificado un hecho como causa del daño no es necesario regresar en la cadena.

\section{F) Criterio de provocación}

Pantaleón sostiene que este criterio se aplica para resolver dos grupos de casos que califica de difíciles. En el primer grupo, este criterio se aplica para imputar objetivamente los daños causados como fruto de una persecución a un delincuente que huye. Todos los daños que se causen en la persecución serán imputables a quien huía siempre y cuando se considere que fue provocada por él ¿cómo se establece si existió provocación? Atendiendo a la razonabilidad y ponderación de riesgos ex ante y las posibilidades de éxito que tenga la persecución.

No se aplicará este criterio cuando la persecución genere mayores riesgos que los bienes que pretende proteger. Por ejemplo, si un sujeto roba un móvil a un niño a la salida de un colegio, no se justifica que la policía abra fuego y persiga al delincuente en una zona donde hay amplia circulación de menores.

En el segundo grupo, quien resulte perjudicado o lesione a otro asumirá su propio daño y el que cause, en su intento de salvar la vida, integridad física o bienes propios o ajenos, de una situación de peligro generada por el responsable ${ }^{85}$. 
En este criterio también habrá que atenerse a la razonabilidad y ponderación del artículo anterior.

La doctrina española ${ }^{86}$ explica este criterio a través de un ejemplo: al culpable de un accidente de tránsito en el que resulta incendiado un vehículo le serán objetivamente imputables los daños que se le causen a una persona que intenta salvar a un niño atrapado en el asiento trasero; sin embargo, no le serán imputables los daños de la persona que intenta salvar el equipaje del maletero.

Recientemente, la sentencia 11/2020 de la AP de Badajoz, sección 3. a , puede contener un ejemplo de este criterio. Una persona pasea sin cadena su perro French poodle (también llamado 'caniche' en España, raza no agresiva) y la mascota es atropellada por un vehículo. Un viandante que observa la escena acude en socorro del perro y resulta mordido por el animal y con lesiones. El asunto desató un interesante intercambio de argumentos entre los profesores García Amado y Pantaleón, atacando el primero la aplicación de los criterios de imputación objetiva y el segundo defendiéndolos ${ }^{87}$.

García Amado considera que el asunto debió resolverse bajo un régimen objetivo en el que ningún papel desempeña la culpa, mientras Pantaleón estima que aunque puede que la sentencia comentada no haya llegado a la decisión más acertada, la solución sí va de la mano de criterios de imputación objetiva como el fin de protección de la norma que, en este caso, a su juicio, tiene como finalidad los animales peligrosos.

El criterio de provocación aquí va de la mano con el interés que se pretende proteger. ¿Se arrojó el viandante a proteger un interés superior en cabeza del perro de acuerdo con los criterios de ponderación y razonabilidad? Según el criterio de provocación debe asumir su propio daño, toda vez que, aunque la situación de peligro fue generada por el demandado, los bienes o intereses que estaban en juego no justificaban la intervención del demandante o podría haber observado una conducta diferente como llamar a las autoridades ambientales.

Con todo, tal como lo reseña el maestro Pantaleón, esta no es la única solución, pues se trata de un caso ciertamente difícil. Enfatizamos en que los criterios de imputación no son excluyentes y puede que, a la luz de otros, también se encuentre solución.

86 Aunque el ejemplo fue originalmente propuesto por Fernando Pantaleón, otros autores lo aplican para ilustrar este criterio: De Ángel, Causalidad en la responsabilidad, 47, y Mariano Yzquierdo, Responsabilidad Civil (Madrid: Dykinson, 2017), 220. 
Este criterio ofrece unos contornos muy especiales, ya que los grupos de casos que pretende resolver parten de un análisis ex ante de razonabilidad y ponderación. Se erige como una alternativa creada desde el derecho privado a la aplicación analógica de la causal de ausencia de responsabilidad penal denominada legítima defensa; una razón importante para considerarlo es la ausencia de antijuridicidad de los sistemas civiles abiertos, frente a lo cual resulta inadecuado aplicar una eximente de antijuridicidad.

\section{G) Criterio de competencia de la víctima}

Este criterio es un aporte del maestro Díez-Picazo y también ha sido aplicado por la jurisprudencia. Estima que si en un contacto social el control de la situación corresponde a la víctima deberá imputarse a ella el daño y no al autor mediato. Con un ejemplo ilustra su criterio: si un elevador tiene capacidad para cuatro personas y suben ocho, éstas tendrán el control de la situación ya que era de su competencia impedir que se excediera el cupo máximo; lo anterior siempre y cuando no exista culpa atribuible al propietario de la máquina ${ }^{88}$.

Se podría circunscribir este criterio al ámbito del reproche subjetivo o culpabilístico, pero el mismo autor considera que pertenece al de la imputación, ya que no se parte de juicios de valor sino de establecer el dominio de la situación ${ }^{89}$. Una situación similar en la doctrina de la guarda en las cosas y actividades peligrosas, con la diferencia de que en la competencia de la víctima es ésta quien controla la situación, mientras que el guardián es el sujeto activo o dañador ${ }^{90}$.

El punto clave de este concepto es el dominio de la situación. El criterio de dominio del hecho en el ámbito civil es una propuesta del profesor Juan A. García, pero es bien sabido que su origen está en el derecho penal bajo la teoría de Claus Roxin ${ }^{91}$.

El criterio de competencia de la víctima, como todos los demás, puede alternarse con otros, como, por ejemplo, prohibición de regreso, pero en especial con el del dominio del hecho, aunque no en la forma de criterio general como lo propone Juan A. García, ya que bajo su hipótesis este absorbería a todos los demás ${ }^{92}$.

Díez-Picazo, Responsabilidad civil, 375.

89 Ídem.

90 Luis Josserand, Derecho civil, t. II (Buenos Aires: Bosch, 1950), 420.

91 Claus Roxin, Autoría y dominio del hecho (Madrid: Marcial Pons, 2016).

92 De hecho, la mayor parte de la doctrina civil española no comparte su posición. Véase Ricardo de Ángel, Causalidad en la responsabilidad, y Luis Regleros, Tratado de responsabilidad civil. 


\section{Estado del arte de la imputación objetiva en la jurisprudencia colombiana}

La aparición de imputación objetiva en la jurisprudencia colombiana es un hecho reciente. La CSJ la mencionó por primera vez como obiter dicta en la sentencia de 2016 y sin referirse a los criterios que la integran. De ahí en adelante se ha venido tratando el concepto, pero no aplicándolo de manera expresa, pues la Corte incluso ha marcado diferencias entre imputación objetiva y lo que denomina imputación civil.

Como señalamos líneas atrás, la CSJ ha aplicado algunos criterios de imputación objetiva, pero sin otorgarles dicho nombre. Sin embargo, en algunos salvamentos de voto se encuentra que el debate aún está latente y lejos de finalizar con una aplicación armónica y uniforme de la doctrina de la imputación objetiva; es decir, la discusión apenas empieza.

En este apartado comentaremos algunas decisiones relevantes de la CSJ en las que se abordan la causalidad e imputación como problemas jurídicos. Destacamos sentencias de los últimos cinco años por motivos de espacio y también porque solo hay una mención expresa del concepto de imputación objetiva a partir del año 2016.

\section{A) Sentencia del 30 de septiembre de 2016, rad. SC 13935-2016}

Un paciente acude al servicio médico con dolor abdominal por apendicitis. Debido a la negligente atención hospitalaria se convierte en una peritonitis, que causa la muerte del paciente. El paciente y sus familiares acudieron en varias ocasiones al centro hospitalario, pero a la víctima no le fue proporcionado el tratamiento adecuado.

En este caso la CSJ resolvió como problema jurídico la responsabilidad patrimonial de las personas jurídicas y la naturaleza jurídica de la responsabilidad civil por daños causados a los usuarios del sistema de seguridad social. Se trata de un extenso pronunciamiento en el que la CSJ emite una sentencia sustitutiva. En uno de los puntos alude a los elementos de la responsabilidad civil y se refiere a la atribución del daño a un agente. Esta mención se hace a título de obiter dictum, pues la sentencia no basa su argumentación en la doctrina de la imputación objetiva.

En primer lugar, la sentencia hace suya la noción de imputación objetiva de Larenz K., citando el conocido pasaje de su obra en donde alude a las causas adecuadas. Sostiene la Corte que debe distinguirse entre causa natural y causa jurídica. 
Afirma que la causalidad natural es insuficiente para la atribución del daño y que en algunos casos bastará la atribución normativa con base en razonamientos de probabilidad.

Consideramos que el concepto que introdujo la CSJ en esta sentencia tiene dos falencias bajo el tamizaje del concepto de imputación objetiva que hemos analizado: (1) erige el criterio de adecuación como preponderante dentro de la imputación objetiva y va más allá: lo confunde con la teoría de la causalidad adecuada. Esta línea de pensamiento no es asimilada en las sentencias de la CSJ, pues, como veremos, en una sentencia del año siguiente ni siquiera menciona la imputación civil, sino que directamente resuelve el caso con el criterio de relevancia jurídica.

(2) No desarrolla los criterios de imputación objetiva que han venido apareciendo en la jurisprudencia y la doctrina comparadas.

Por el contrario, pretende establecer distancia con la imputación objetiva penal al sostener que es prácticamente imposible aplicarla en el ámbito civil debido a que la primera alude al reproche de la conducta. Nos alejamos de esta forma de argumentar, puesto que, como se vio, los criterios de imputación objetiva en el derecho de daños no son juicios de valor de la conducta sino elementos que permiten establecer la relevancia jurídica de los hechos que componen la cadena causal operando como límites a la teoría de la equivalencia de las condiciones.

En conclusión, se afirma la existencia de la imputación objetiva, pero se niega su aplicación práctica porque se confunde con el criterio de adecuación y no desarrolla los criterios que la jurisprudencia y doctrina comparada han propuesto para su aplicación en el derecho de daños. Sin embargo, el mérito de esta sentencia radica en la enunciación de la teoría de Larenz y la distinción entre causa natural y causa jurídica, aunque no utilice para resolver el caso.

El salvamento de voto del magistrado Quiroz pone de presente que la Sala olvida tener en cuenta las teorías de la causalidad y critica que la sentencia intente sustituirlas por juicios probabilísticos, lo cual acontece bajo el imperio del criterio de adecuación. Nos adherimos a esta postura, puesto que bajo el marco conceptual de imputación objetiva la causalidad natural no se descarta, sino que se limita a través de sus criterios.

\section{B) Sentencia del 29 de marzo de 2017, rad. SC 9193-2017}

Un menor de edad sufrió graves daños cerebrales como consecuencia de la deficiente atención médica que recibió su madre durante el parto. En esta sentencia la CSJ aplica de forma tácita la teoría de la causalidad adecuada. Uno de sus 
argumentos es la probabilidad prevalente, la cual se aplica de acuerdo con los dictámenes periciales aportados en el proceso. Esto ha dicho la CSJ:

También quedó demostrado que el cordón umbilical teñido de meconio reciente, la acidosis metabólica, la asfixia perinatal y la deglución de sangre materna, son signos que la ciencia médica describe como síntomas de sufrimiento fetal; mientras que la circunstancia de que fuesen recientes al momento del nacimiento indica, con un alto grado de probabilidad, que de haber recibido la gestante y el feto una atención oportuna y necesaria según los signos que presentaba la embarazada desde hacía varios días, no se habría producido la lesión neurológica en el recién nacido.

Aunque compartimos la decisión, no estamos de acuerdo con los argumentos de la sentencia ya que el juicio de atribución se basa exclusivamente en la probabilidad y en la construcción de hipótesis indiciarias para establecer dicha probabilidad. Esta forma de razonar hace ver el juicio de atribución como un elemento casi que presunto puesto que para arribar a la conclusión no se examinan criterios como el fin de protección de la norma, el cual habría sido útil para argumentar la incidencia causal de la actividad del demandado.

Finalmente, nótese que esta sentencia es posterior en el tiempo a la que acoge la imputación objetiva de Larenz K., pero aun así la teoría o criterio aplicado es el de adecuación; se pone en evidencia que aún no hay un consenso sobre el concepto de imputación objetiva, y aunque se le denomine de esa manera, en el fondo lo que subsiste es el criterio de adecuación.

\section{C) Sentencia del 12 de enero de 2018, rad. SC 002-2018}

Una persona fallece por electrocución al tropezar con cables de electricidad en mal estado aledaños a su vivienda. La víctima intentaba instalar un marco metálico, que hizo contacto con los cables. También sufrió lesiones su cónyuge al intentar auxiliarlo. En esta sentencia hay un mayor acercamiento conceptual a la imputación objetiva. A diferencia de la sentencia de 2016, la CSJ no desconoce la causalidad natural, ni la sustituye por juicios de probabilidad.

El alto tribunal propone que los criterios de imputación se encuentran en el ordenamiento jurídico y son aprehensibles para los jueces. Sin embargo, no menciona criterio diferente al de la relevancia jurídica, esto es, adecuación. Reitera la reticencia de la CSJ a aplicar la imputación objetiva penal, agregando nuevos argumentos como el rechazo al criterio del riesgo permitido. 
Sostiene la sentencia que en el derecho civil todos los riesgos son permitidos y no cabría aplicar dicho criterio que parte del paradigma funcionalista. Considera que es un concepto que nada aporta a la responsabilidad civil. Esta concepción se origina en el régimen sui generis del artículo 2356 del CC, que alude a las actividades peligrosas. De acuerdo con la CSJ, es un régimen subjetivo de culpa presunta en el que no es posible exonerarse alegando diligencia y cuidado. Esto se traduce en que realmente estamos frente a un régimen objetivo, aunque la sentencia lo niegue y diferencia entre éste y el de culpa presunta; no puede ser subjetivo un régimen en el que únicamente es posible liberarse por una causa extraña.

El criterio de riesgo permitido en el ámbito del derecho de daños alude a la conducta alternativa correcta, lo cual no se toma en consideración en la sentencia porque se aplica como criterio de imputación subjetiva y no objetiva. Esta conclusión emerge con claridad del uso en la sentencia de la previsibilidad de la conducta y su calificación como riesgosa. Si se aplicara como criterio de imputación objetiva, tendría lugar en el nexo causal y no en el juicio de culpabilidad. Con todo, aún en la jurisprudencia española se debate si en verdad se trata de un criterio subjetivo u objetivo; la duda se amplía cuando estamos frente a actividades riesgosas.

Llama la atención el hecho de que la sentencia cuenta con dos aclaraciones de voto y un salvamento, pero lamentablemente no se encuentran disponibles en la versión digital de la sentencia. No obstante, este hecho es indicativo de que esta decisión no representa un consenso de la sala, sino que puede que haya discrepancias conceptuales y argumentativas.

\section{Conclusiones}

La teoría de la imputación objetiva en el derecho de daños se ha constituido en una herramienta fundamental para solventar los juicios de atribución con mayor precisión, argumentación y cientificidad que la aplicación singular de las tradicionales teorías de la causalidad.

El hecho de partir de la teoría de la equivalencia permite analizar en toda su amplitud la cadena causal y con la aplicación de los criterios es posible escoger los hechos que son relevantes para el universo jurídico. Dentro de los criterios encontramos algunos que pueden ser útiles para descartar cursos causales irrelevantes tanto en el plano físico como en el jurídico, como lo es el caso de la prohibición de regreso. 
Sin embargo, consideramos que aún hoy el criterio de adecuación sigue siendo de mayor aplicación por parte de los jueces, aunque su uso se alterne o combine con otros como el de fin de protección de la norma.

La imputación objetiva se plantea como propósito establecer diferencias entre el juicio de culpabilidad y el de atribución. No obstante, a pesar de que esta división es aparentemente clara cuando se explican los criterios en las sentencias que analizamos, se pudo ver que en ocasiones la imputación termina siendo subjetiva en lugar de objetiva. Por ejemplo, en el criterio de incremento del riesgo uno de los postulados fundamentales es la previsibilidad; esto nos deja en el mismo lugar de los juicios de probabilidad de la causalidad adecuada, y, peor aún, podría entenderse dicha previsibilidad como un deber de conducta que se traduce en un factor de atribución de culpa.

EI TSE aplica los criterios de imputación objetiva, aunque los denomina de diferentes formas. No existe un acuerdo total en la jurisprudencia y en la doctrina sobre cuáles son los criterios de imputación objetiva, pero lo cierto es que en las sentencias reseñadas el problema de la imputación es abordado de forma sistemática y señalando, en algunos pronunciamientos, qué teoría causal o criterio se aplica para resolver el caso.

En Colombia, a pesar de que la CSJ estima que la imputación civil es uno de los elementos de la responsabilidad extracontractual, el desarrollo del concepto se acerca más a la teoría de la causalidad adecuada que a los criterios de imputación objetiva. Esto quedó muy claro en las sentencias reseñadas, pues en los argumentos se invoca sin reservas la probabilidad preponderante y la construcción de hipótesis indiciarias para resolver los casos.

Sin embargo, se trata de un concepto en construcción y constituye un avance importante en la jurisprudencia de la CSJ que por mucho tiempo se resistió a introducir nuevos avances doctrinales en materia de imputación. Las sentencias que se analizaron al menos no dejan el juicio de imputación como un asunto presunto o implícito; aluden a dicho elemento y van más allá de la simple relación de causa a efecto aplicando criterios jurídicos para establecer la relevancia causal.

En los salvamentos y aclaraciones de voto la discusión está latente. Aunque las decisiones de la CSJ son acertadas y compartidas, no así la argumentación para llegar a las conclusiones. Es por ello por lo que resulta de vital importancia hacer seguimiento a las sentencias, los salvamentos y aclaraciones para poder identificar los avances en la materia, pues en ocasiones de estas posiciones minoritarias se desprenden las más acertadas conclusiones. 
El elemento imputación reviste ingente importancia dentro del juicio de responsabilidad patrimonial debido a que su función consiste en determinar sobre qué patrimonio ha de recaer la obligación de reparar el daño. Un correcto entendimiento de la figura ayudaría a una mejor aplicación de la reparación integral de las víctimas y a su vez a no extender de forma injusta el espectro de la reparación a cargo del dañador.

Finalmente, siguiendo al maestro De Ángel, es necesario concluir afirmando que los criterios de imputación objetiva pueden convivir de forma armónica con el resto de las instituciones de la responsabilidad civil, pues su intención no es desplazar las estructuras existentes sino crear nuevas alternativas que permitan a los jueces aplicar con mayor cientificidad el derecho de daños y por ende lograr una adecuada compensación y justicia correctiva.

\section{Referencias}

Alonso, Mariano. "Ideal codificador, mentalidad bucólica y orden burgués en el código civil de 1889", en Centenario del código civil (1889-1989). Asociación de Profesores de Derecho Civil, vol. I, Madrid: Centro de Estudios Ramón Areces, 1990.

Ángel Yágüez, Ricardo de. Causalidad en la responsabilidad extracontractual: sobre el arbitrio judicial, la "imputación objetiva" y otros extremos. Cizur Menor: Civitas, 2014.

Busto Lago, José Manuel. La antijuridicidad del daño resarcible en la responsabilidad civil extracontractual. Madrid: Tecnos, 1998.

Coleman, Jules. Riesgos y daños, Madrid: Marcial Pons, 2010.

European Group on Tort Law. Principios europeos de responsabilidad civil [cited 10-23 2019]: http://civil.udg.edu/php/biblioteca/items/298/ PETLSpanish.pdf.

García, Juan A. "Sobre algunos mitos del derecho de daños. Causas que no causan e imputaciones bastante subjetivas". En Derecho de daños, Mariano Herrador (dir.). Cizur Menor: Aranzadi, 2013.

García, Juan A. "Bailando con caniches: o de cómo desactivar la responsabilidad objetiva invocando la imputación objetiva", en Almacén de Derecho (2020), https://almacendederecho.org/bailando-con-caniches-o-de-co mo-desactivar-la-responsabilidad-objetiva-invocando-la-imputacionobjetiva. 
Hegel, Georg Wilhelm Friedrich y José Gaos. Lecciones sobre la filosofía de la historia universal. Puerto Rico: Universidad, 1953.

Hegel, Georg Wilhelm Friedrich. Fenomenología del espíritu. Valencia: Pre-textos, 2006.

Honoré, Anthony. "Causation and remoteness of damage", en International Encyclopedia of Comparative Law, ed. David René y André Tunc, vol. XI Torts. Tübingen [etc.] (gw): J. C. B. Mohr (Paul Siebeck), 1983.

Jakobs, Günter. Derecho penal / parte general fundamentos y teoría de la imputación. Madrid: Marcial Pons, 1997.

Josserand, Luis. Teoría general de las obligaciones. Derecho civil, trad. Santiago Cunchillos y Manterola, t. II, vol. I. Buenos Aires: Bosch, 1950.

Kant, Immanuel, Adela Cortina Orts y Jesús Conill Sancho. La metafísica de las costumbres. Madrid: Tecnos, 1994.

Larenz, Karl y Jaime Santos Briz. Derecho de obligaciones. Madrid: Revista de Derecho Privado, 1958.

Maraver, Mario. "Consideraciones sobre la teoría de la imputación objetiva, en derecho civil y en derecho penal. A propósito del libro de Martín García Ripoll Montijano, imputación objetiva, causa próxima y alcance de los daños indemnizables", en Anuario de Derecho Civil, LXIII (I) (2010): 335. https://www.boe.es/publicaciones/anuarios_derecho/abrir_pdf. php?id=ANU-C-2010-10033500348.

Markesinis, Basil. A Comparative Introduction to the German Law of Torts. Oxford: Clarendon Press, 1994.

Mir Puig, Santiago, Víctor Gómez Martín y Vicente Valiente Ivañez. Derecho penal. Parte general, décima edición, Barcelona: Reppertor, 2016.

Montés Peñadés Vicente. "Causalidad, imputación objetiva y culpa en la "concurrencia de culpas»", en Estudios jurídicos en homenaje al profesor Luis Díez-Picazo, t. II, Derecho civil: Derecho de obligaciones, Díez-Picazo, Luis y Cabanillas Antonio (eds.), vol. Il. Madrid: Thomson, 2003.

Pantaléon, Fernando. "De las obligaciones que nacen por culpa o negligencia", en Comentario del código civil, 1972. Madrid: Ministerio de Justicia, Centro de Publicaciones, 1991.

Pantaléon, Fernando. "Causalidad e imputación objetiva: Criterios de imputación”, en Centenario del código civil (1889-1989), vol. II, ed. Asociación de Profesores de Derecho Civil, 1561. Madrid: Centro de Estudios Ramón Areces, 1990. 
Pantaléon, Fernando. Del concepto de daño. Hacia una teoría general del derecho de daños. Universidad Autónoma de Madrid, 1990.

Patiño, Héctor. "Responsabilidad extracontractual y causales de exoneración. Aproximación a la jurisprudencia del Consejo de Estado colombiano", Revista de Derecho Privado, 14 (2008), Universidad Externado de Colombia: https://revistas.uexternado.edu.co/index.php/derpri/article/ view/555.

Patiño, Héctor. "El bípode o el trípode: la estructura de la responsabilidad”, en Responsabilidad extracontractual del Estado: ¿qué?, ¿por qué?, ¿hasta dónde? Henao Juan y Andrés Ospina (eds.). Bogotá: Universidad Externado de Colombia, 2015.

Reyes, Yesid. Imputación objetiva. Bogotá: Temis, 1994.

Roxin, Claus y Joaquín Cuello Contreras. Autoría y dominio del hecho en derecho penal. Madrid: Marcial Pons, 2016.

Roxin, Claus, Diego-Manuel Luzón Peña y Javier de Vicente Remesal. Derecho penal: Parte general, t. I, Fundamentos: la estructura de la teoría del delito. Madrid: Civitas, 1997.

Savigny, Fiedrich Karl Von y Anton Friedrich Justus Thibaut. La polémica sobre la codificación. Santiago de Chile: Olejnik, 2018.

Schawartz, Gary. "Causation under US law", en Unification of Tort Law: Causation, Jaap Spier y Francesco Donato Busnelli (eds.). The Hague, etc.: Kluwer Law International, 2000.

Sierra Gil de la Cuesta y Ricardo de Ángel Yágüez. Tratado de responsabilidad civil. Barcelona: Bosch, 2008.

Sirtori, Eduardo, Responsabilidad patrimonial de la FGN en los juicios por privación injusta de la libertad (trabajo sin publicar para optar al título de máster).

Tamayo, Javier. Tratado de la responsabilidad civil, vol. I. Bogotá: Legis, 2007.

Uribe, Saúl, "El caos dogmático en la responsabilidad civil", en Responsabilidad civil y del Estado, n. ${ }^{\circ} 20$ (Medellín: IARCE, 2006).

Vaquer Aloy, Antoni. "El soft law europeo en la jurisprudencia española: doce casos". Ars luris Salmanticense, I (junio, 2013): 93-115, http://re vistas.usal.es/index.php/ais/article/view/10109. 
Viney, Geneviève. Tratado de derecho civil introducción a la responsabilidad, trad. Fernando Montoya. Bogotá: Universidad Externado de Colombia, 2007.

Yzquierdo, Mariano. Responsabilidad civil extracontractual. Parte general: Delimitación y especies. Elementos, efectos o consecuencias. Madrid: Dykinson, 2017.

\section{Jurisprudencia}

Audiencia Provincial de Alicante, sección 9. ${ }^{a}$, sentencia 219/2017 del 15 de mayo de 2017.

Audiencia Provincial de Almería, sección 3. ${ }^{a}$, sentencia 133/2014 del 30 de julio de 2014.

Audiencia Provincial de Badajoz, sección 3. ${ }^{a}$, sentencia 11/2020 del 30 de julio de 2014.

Audiencia Provincial de Santa Cruz de Tenerife, sección 3. ${ }^{a}$, sentencia 416/2017 del 24 de noviembre.

Corte Suprema de Justicia Colombia, Sala de Casación Civil, sentencia del 30 de septiembre de 2016, SC-13935.

Corte Suprema de Justicia Colombia, Sala de Casación Civil, sentencia del 2 de marzo de 2016, SC2506-2016.

Corte Suprema de Justicia Colombia, Sala de Casación Civil, sentencia del 29 de marzo de 2017, SC 9193-2017.

Corte Suprema de Justicia Colombia, Sala de Casación Civil, sentencia del 12 de enero de 2018, SC 002-2018.

Tribunal Supremo español, sala $1 .^{\text {a }}$ de lo civil, sentencia 147/2014 del 18 de marzo.

Tribunal Supremo español, sala $1 .^{a}$ de lo civil, sentencia 194/2006 del 2 de marzo de 2006.

Tribunal Supremo español, sala $1 .^{\text {a }}$ de lo civil, sentencia 149/2007 del 22 de febrero de 2007.

Tribunal Supremo español, sala 1 . $^{a}$ de lo civil, sentencia 701/2015 del 22 de diciembre de 2015.

Tribunal Supremo español, sala $1 .^{\mathrm{a}}$ de lo civil, sentencia 64/2011 del 09 de febrero de 2011. 
Tribunal Supremo español, sala 2. ${ }^{\text {a }}$ de lo civil, sentencia 717/2017 del 24 de febrero de 2017.

Tribunal Supremo español, sala 2. ${ }^{a}$ de lo civil, sentencia 294/27 de mayo de 2019.

\section{Legislación}

Ley 84 de 1853 (Código Civil colombiano), Diario Oficial n. ${ }^{\circ} 2.867,31$ de mayo de 1873 .

Ley 906 de 2004 (Código de Procedimiento Penal colombiano), Diario Oficial n. ${ }^{\circ} 45.658,1 .^{\circ}$ de septiembre de 2004. 